\title{
LIBERAL DEMOCRACY AND THE CHALLENGE OF ETHICAL DIVERSITY*
}

\author{
ENZO ROSSI
}

\begin{abstract}
What do we talk about when we talk about ethical diversity as a challenge to the normative justifiability of liberal democracy? Many theorists claim that liberal democracy ought to be reformed or rejected for not being sufficiently 'inclusive' towards diversity; others argue that, on the contrary, liberalism is desirable because it accommodates (some level of) diversity. Moreover, it has been argued that concern for diversity should lead us to favour (say) neutralistic over perfectionist, universalistic over particularistic, participative over representative versions of liberal democracy. This paper provides a conceptual framework to situate those debates, and argues that there are two fundamental ways in which diversity constitutes a challenge to the justificatory status of liberal democracy: consistency (whereby diversity causes clashes between the prescriptions generated by normative political theories), and adequacy (whereby diversity generates a rift between our experience of what is considered valuable and what the theory treats as such).
\end{abstract}

Keywords: liberalism; democracy; diversity; pluralism; citizenship.

\section{Introductory}

The idea that the fact of societal disagreement about values, ideals, conceptions of the good and so on, plays or should play an important role in defining the justificatory status of normative political theories, and of liberal theories in particular, seems rather widespread in recent debates on the foundations of participative liberal democracy. ${ }^{1}$ It is common to find theorists claiming that liberalism, or liberal democracy, ought to be reformed or even rejected on the grounds of it not being sufficiently 'inclusive' towards a variety of values and conceptions of the good (Crowder 1994, Kekes 1992, Parekh 2000); others argue that, on the contrary, liberalism is preferable to most other normative political theories because it allows for the accommodation of (some level of) ethical diversity (Berlin 1958, Berlin and Williams 1994, Larmore 1994, Williams 1980). Those are positions on the external front of the debate on the foundations of liberal democracy: they concern the very justification of liberal democracy

\footnotetext{
* We acknowledge the support of the European Commission's 6th Framework Programme and the EuroEthos Research Project.

1 This may be culturally connected to a broader trend towards an interest in what goes under the umbrella-term of 'pluralism', an interest that many have recognized in the parlance of many fields of the contemporary social and human sciences. On this point, see for example the survey provided by McLennan (1995); I have briefly addressed the issue in Bardone, Rossi (2004, 13-15; 19n). And in turn the interest in 'pluralism' may stem from changes in the broader historical context. However, discussing those compelling and vast issues would go far beyond the aims (and, more importantly, the limitations) of the present study.
} 
as opposed to other political systems. There are analogous disputes on the internal front as well: it has been argued that some sort of concern for diversity should lead us to favour (say) redistributivist over libertarian, neutralistic over perfectionist (Larmore 1994; for the opposite view, see Raz 1986 or Galston 2002), universalistic over particularistic versions of liberalism (Crowder 2002). More generally, and cutting across the two fronts outlined above, diversity is often seen as a source of challenges to the effective participation of citizens in the public life of contemporary liberal democracies. The aim of this paper is to provide a conceptual framework to map and situate those debates. In other words, I shall try to understand in what sense, if in any, (the accommodation of) ethical diversity is important for and poses a challenge to the justification of liberal democracy.

I will proceed as follows. In the first section I draw a distinction between two senses in which ethical diversity can pose a problem for the justificatory status of a normative political theory. The following two sections analyze how each of these sources of problems, or challenges, respectively play out in the debates on the justification of liberal democracy. Certainly it will not be possible to provide a complete map of all the positions in the debate, and neither do I aspire to do so here; I would just like to present a method of analysing those positions from the point of view of the challenges of ethical diversity. The final section, then, briefly assesses the significance of the issues raised by this analysis. It does so by offering a few directions for further work about the problem of the role of ethical diversity in the foundations of liberal democratic political practice.

\section{Confronting Diversity: Two Challenges}

Let us start where most debates about the role of ethical diversity in the justification of liberalism start, namely from the acknowledgment of the fact that people disagree about values, ideals, conceptions of the good, and so on. What is more, the disagreement seems to be here to stay: there seems to be no tendency towards the disappearance of such disagreement. Call this the fact of ethical diversity. ${ }^{2}$ While in principle such a state of affairs could come about in any context, it seems to be characteristic of contemporary liberal democratic societies more than of any other environment. Indeed, liberal societies have traditionally been characterized by the coexistence of a diversity of ethical outlooks. Some even argue that they have been devised in response to the problems posed by the ethical fragmentation-to borrow Thomas Nagel's famous phrase_of early-modern European societies (Shklar 1989, Rawls 1993, xxvi ff). However, it seems important to note that surely there has been a very significant increase in the level of cultural (and hence ethical) diversity in recent times, with the most radical changes perhaps taking shape from the twentieth century. (For a historical survey-limited to Europe, though — of the nature and impact of those changes, see Galasso 1996, 775-785.) Thus, while in the seventeenth or eighteenth century a society where Catholics, Protestants, and perhaps Jews coexisted would have been considered ethically diverse, nowadays it would seem rather homogeneous. And these changes could explain (historically rather than conceptually) why

\footnotetext{
2 The relevant fact here is one of interpersonal disagreement, or diversity: people disagree with each other. There is of course also intrapersonal ethical diversity, i.e. conflicts of values within individuals. Much has been written about intrapersonal diversity, and about how it is connected to interpersonal diversity; however those issues are beyond the scope of this paper. For a useful discussion of how intrapersonal diversity could affect the justificatory status of (some of) the claims of liberalism, see Carter 2004.
} 
arguments from ethical diversity have become so common in discussions of the foundations of liberalism over the past few decades. ${ }^{3}$

So, many arguments for and against liberal democracy proceed from the fact of diversity; but they have to go a rather long way before they become interesting, at least from a normative or justificatory point of view. That is to say that clearly the fact of diversity per se generates no normative conclusions relevant to the issue of the justification of liberalism. Noting that there is disagreement about values does not tell us what to do about it. So why should this fact be important? The idea here seems to be that liberalism deals, or copes with this fact better (or worse) than other theories. But what could this mean? How could the fact of diversity cause problems to liberalism, or indeed to any normative political theory? It seems to me that there are two ways in which this could be the case (or two senses in which we can say that a theory 'deals' or 'copes' with diversity), one direct and one indirect. That is to say that, in my view, most arguments from ethical diversity can be understood as stemming from one of those two potential sources of problems, or challenges. In this section I shall explain what I take those challenges to consist in. Providing an account of how they play out in debates on the foundations of liberalism (and showing why it is useful to conceptualize through the idea of the two challenges), then, will be the object of the next two sections.

Let us begin from a distance, with the indirect challenge. We may call it the challenge of consistency. A first, intuitive, way of putting the point would be to say that the fact of diversity brings to our attention inconsistencies in the prescriptions generated by normative political theories, inconsistencies which would not have emerged had it not been for the fact of diversity. To clarify, consider the example of a normative political theory containing the following two prescriptions:

1. All citizens ought to be allowed to practice their religion without restrictions, unless those religious practices cause actual, direct harm to other groups or individuals.

2. All citizens, when in public places, ought to show their face at all times, in order not to obstruct identification by the police.

There appears to be no inconsistency between 1 and 2, or at least that is what one would be inclined to think in a relatively homogeneous society—one populated just by (say) Christians of various denominations, secular humanists, and Sikhs. However, as soon as Muslim women wearing the burqa or the chador become part of the citizenry, we realise that our normative theory indeed yields a contradiction: under conditions of diversity of a certain sort, it becomes impossible to pursue both the goal of freedom of religious practice and that of effective police

I said "arguments from ethical diversity" in order to mark the difference between the discussions of diversity in classical texts of the liberal tradition such as Locke's Letter Concerning Toleration and Mill's On Liberty and the contemporary discussions I am concerned with here. The difference is this. Liberals of the past discuss ethical diversity and its accommodation as a side issue in their theories: they discuss it in order to elucidate one of the implications of their views on natural law and individual rights, the role of religion in civil society, autonomy (or 'individuality', in Mill's parlance) and wellbeing, and so on. That it to say that if one were to show that, say, Locke's view on toleration is flawed, or does not follow from his broader arguments for liberalism, those arguments could still remain in place. On the other hand, many contemporary political philosophers present the issue of ethical diversity as crucial to the justification of liberalism: as I pointed out in the introductory section, they seem to think that the issue of diversity can, by itself, somehow constitute the core of the justification or the refutation of a normative political theory. One of the main aims of this paper is indeed to understand whether there is a sense in which this could be the case. 
supervision of public places. ${ }^{4}$ The idea here is that the fact of diversity actualizes what in a more homogeneous society would have been just a logical possibility. An objection to a normative theory based on this issue, then, is one that points to the incompatibility between a particular normative theory and a particular context. That should make clear why I have labelled the challenge of consistency an 'indirect' challenge: it does not affect the theory per se, but the relation between the theory and its context of application.

To return to our initial concern, then, we can say that one sense of the claims about a normative theory's ability to 'cope' or 'deal' with ethical diversity is this: a theory is able to cope with diversity if the emergence of conditions of ethical diversity in the society where the theory is meant to be applied does not give rise to inconsistencies between the theory's claims. ${ }^{5}$ In the next section we shall consider this initial characterization of the challenge of consistency in more detail, in order to see exactly what sort of issues in the debates on the foundations of liberalism are connected to it. ${ }^{6}$

We can now turn to the direct challenge, which I will call the challenge of adequacy. It is a direct challenge because, as we shall see shortly, it affects the type of arguments needed for the justification of a normative political theory. To understand what this challenge consists in, reflect on our everyday experience of what is valuable to us and to others in an ethically diverse society: we are confronted with a plurality of incompatible values, conceptions of the good life, and so on. Moreover, we typically do not expect this disagreement to fade away, and all people to converge towards a single conception of the good or ranking of values. Because of this incompatibility, any plausible normative theory must make some choices as to what values to promote, or even just tolerate, and what to exclude. ${ }^{7}$ (I am of course assuming that coherence is a necessary condition for the plausibility of any such theory. Also note that, at least in

\footnotetext{
4 If the formulations in terms of an issue of 'consistency' were to look awkward, it may be useful to note that the point could also have been put in terms of a theory's ability to realize its aims under conditions of diversity (as suggested by the sentence to which this footnote refers). It seems to me that, as it will become clearer later on, these two alternative (but substantially equivalent) ways of presenting what on the whole is the same issue, may explain why two different debates, one about 'stability' and one about 'realism', can be analyzed in terms of such an issue, which I have termed 'the challenge of consistency'.

5 This becomes particularly salient when we consider theories such as liberalism, which have been designed in contexts far more ethically homogeneous than most of those where they are currently applied. But that is not the only important issue that is captured by my account of the challenge of consistency. Indeed, the account also helps to understand arguments that a political theory is not 'realistic'. The point here is that the lack of 'realism' could be characterized as an inconsistency between one of the theory's explicit commitments or aims (avoiding violence between the citizens, say), and an implicit commitment that we can take any theory to have, namely that of being actually applicable.
}

${ }^{6}$ Of course, it makes a difference whether there is an entailment relation (and what sort of relation it is) between the claims of the normative theory that have become inconsistent in the light of the fact of diversity or not: the theory may have to be abandoned altogether, or revised to some extent (which in turn would raise the further issue as to whether the changes compromise the identity of the theory), and so on. Expanding on these matters, however, would be beyond our scope here.

7 There is a (rather irrelevant) sense in which this is true of ethically homogeneous societies as well. Imagine a society where everybody agrees on a single ranking of values or conception of the good life. The normative theory regulating political life in this society is also based upon this conception of the good. Now the point is that, at least in principle, even in such a society one should consider the other conceivable alternative conceptions. The fact of agreement does not per se dissolve the challenge of diversity, even though finding a response to it would become little more than an academic exercise. So 
principle, a theory need not be based on a subset of the set of values that are actually held by the citizens it is supposed to govern: it may very well propose radically new values, cultural revolution style.) To put it more precisely, we can say that any theory must provide a ranking of those values and conceptions of the good, such that some will be treated as more valuable than others, and possibly some will not be treated as valuable at all. Now the problem is that, in a society characterized by a fairly high level of ethical diversity, no precise ranking presents itself to our experience as convincingly binding for all ${ }^{8}$ - often it actually seems unlikely that there could even be such a ranking. ${ }^{9}$ The challenge faced by a normative political theory, then, consists in justifying its ranking of values, in the face of our perception of the absence of clear grounds for such a ranking. ${ }^{10}$ In other words, the challenging task is that of overcoming the perception of too large a rift between our experience of what is valuable to us and to others, and what the theory prescribes to treat as such. That should also explain why I have (perhaps clumsily) labelled this problem 'the challenge of adequacy': a normative political theory should provide an adequate account of how to bridge the rift I have just described.

To clarify this point, consider a crudely simplified model of the structure of the arguments through which normative theories respond to this challenge. Let us use the example of Plato's political philosophy (or rather 'Plato"s, for what I will present is just a parody of his views, hypersimplified for the purpose of illustrating my point). The structure of the 'platonic' response to the challenge of adequacy could be presented as follows:

1. Acknowledgement of the fact of diversity: There is disagreement about what values and conceptions of the good are worth including in the polity. Most citizens think that the aim of the state should be to enable them to pursue their material well-being; others believe that the polity ought primarily to pursue military honour; a further (small) group think that, in virtue of their superior knowledge and understanding, they should be allowed to rule the polity and impose their conception of the good upon the rest of the citizenry.

2. Argument(s) justifying a particular ranking of values: The nature of value is such that only through careful study and understanding is it possible to know how best to rule the polity. This is the case because the good is an abstract idea which can only be grasped through

for example, the normative political theory embodying the universally shared conception of the good could contain an argument that convergence on a single conception of the good is sufficient grounds for ruling out alternative conceptions (for epistemic and/or prudential reasons, say).

8 "A fairly high level of ethical diversity": Surely this is a rather vague formulation. However, I just hope it is clear enough to convey the simple point that the more diverse the society, the harder it becomes to cope with the challenge of adequacy.

9 As it is well known, there is a large body of work in decision theory (stemming from the seminal work of Kenneth Arrow) concerning precisely the point of what level of previous agreement is necessary for a group of agents with heterogeneous preferences (or values) to reach an agreement over a decision procedure to determine a ranking of those values (such as a set of rules governing political life in a diverse society). For an interesting discussion of the implications of these debates for the justification of liberalism in a diverse society, see D'Agostino 2004.

${ }^{10}$ Something sociological should probably be said at this point. Clearly the mere fact of diversity does not automatically cause people to start seeing the realm of value in this pluralistic fashion, at least not immediately (just imagine how one of our medieval ancestors would react if she were to travel to a metropolis of the twenty-first century!). However, I take it that, in most contemporary diverse societies, most people have developed such a pluralistic sensibility. It seems at least plausible to say that if this were not the case, we would witness far more social strife than we actually witness. 
rational inquiry and contemplation, etc. Thus the latter group's conception of the good is the only correct one, and they are more likely to be good rulers than any of the other groups.

Argument(s) explaining away the fact of diversity: The first two groups have those misguided beliefs about what is valuable and how the polity should be ruled because they have not formed their beliefs through careful study, but by giving in to passions and instincts (these are not reliable ways of forming correct beliefs about how to run a state). In fact they are not suited for higher understanding, for they belong to an inferior breed of human beings: they were formed from bronze and silver respectively, whereas the latter group were formed from gold. Moreover, it turns out that the characteristics of each of the inferior groups are such that they can only live well when directed by the more knowledgeable group.

3. Normative conclusion (following from 2): The golden people ought to rule the polity according to their conception of the good.

What this presentation of a somewhat amusing theory shows is that the parts which are most relevant here, i.e. the parts engaging with the challenge of adequacy, are those described in point 2 and 2.1 (note that, of course, this need not be the only possible structure of a response to the challenge of adequacy: the tasks carried out in 2 and 2.1 may very well be covered by a single argument). So, in order to successfully overcome the challenge of adequacy, a normative political theory should provide us with convincing grounds to abandon our prima facie judgments on the nature of value.

Now that may seem just an intricate way of putting the obvious point that any normative theory should contain arguments in support of its claims or prescriptions. And in a sense it is; but there is a reason for putting it this way here. It is indeed useful to highlight that the fact of diversity constitutes a particular type of hurdle for the justification of normative theories: it makes it necessary for normative theories to overcome a particular kind of resistance. As we have just seen, diversity is a hurdle in the sense that it needs to be explained away, one way or another. There is indeed a prima facie or phenomenic structure of value, namely the fragmented one we experience in ethically diverse societies, and there is the 'real' structure of value, which every particular normative theory characterizes in its own way. The point is simply that ethical diversity places higher demands on the way normative theories should argue for their claims, at least from one aspect (namely the aspect of matching our quotidian impressions of what is valuable). In fact, hardly anyone would deny that, for an advocate of an evangelic Christian theocracy (say), the justificatory hurdle to jump in a rural Amish community is much lower than the one she would face in Manhattan. Likewise, our account of the challenge of diversity tells us that, in an ethically diverse society, a normative political theory which prescribes to treat as valuable a plurality of values and conceptions of the good will have a competitive edge over a less inclusive theory (other things being equal, of course).

This way of putting the problem is also consistent with, or rather explains, what seems to be a near-universal attitude among contemporary political theorists: ceteris paribus, a theory which is more inclusive towards ethical diversity is to be preferred to a less inclusive one-it is to be preferred precisely because it is easier to reconcile it with our direct impressions of the nature of value. The least inclusive the theory, the stronger the arguments in its favour should be, other things being equal, of course. ${ }^{11}$

${ }^{11}$ To add a slightly polemic consideration, one may note how some writers seem to almost disregard the ceteris paribus clause altogether, thus regarding the test of inclusiveness as a 'make or break' 
The second sense in which we can say that a theory 'deals' or 'copes' with ethical diversity, then, could be roughly spelled out as follows: a theory copes adequately with diversity if its claims, which necessarily weed out or penalize some values and conceptions of the good which we would not be inclined to dismiss easily, retain their persuasiveness against our prima facie judgements of value. That is a thumbnail sketch of the challenge. We shall look more closely at it below, as we will try to understand how it can affect the justificatory status of liberal democracy.

To sum up, in this section we have identified two senses in which ethical diversity could pose a problem for the justification of a normative political theory: diversity can pose problems of consistency and problems of adequacy. In what follows I shall provide an account of how these problems affect contemporary debates on the justification of liberal democracy.

\section{Consistency, Stability and Realism}

Recall our initial characterization of the challenge of consistency. We have seen that one of the senses in which the fact of ethical diversity may be a problem for the justificatory status of a normative political theory can be explained, roughly speaking, in terms of a problem of compatibility between a theory's claims and the context where the theory is supposed to be applied. Now, as anticipated, it seems to me that this characterization can provide a conceptual framework useful when thinking about some related issues (or families of issues) that are often discussed in contemporary debates on the foundations of liberalism under the broad labels of the problems of 'stability' and 'realism'. This section provides an account of how those debates can be analyzed within the framework of the challenge of consistency, and thus be reduced to the same issue (one of consistency, indeed). Hopefully this analysis will help us clear the ground of some sources of possible equivocation about what is at stake in those debates.

In what sense can problems about the 'stability' and the 'realism' of a normative political theory, and in particular of liberalism, be reduced to a matter of consistency? To answer this question, consider the challenge of consistency as an indirect challenge: it concerns how a theory is affected by its context of application. Both stability and realism are also best understood as problems not inherent to a theory, but generated by the interaction between a theory and some external circumstances. More precisely, between a theory and the changes that occur in the context in which it is meant to be applied. In fact, the issue of stability is usually presented in terms of whether (or to what extent) a political theory that has been devised in a context of limited ethical diversity can maintain its justificatory status when confronted with a context characterized by a higher level of diversity. Similarly, the problem of realism is often presented as one of whether conditions of ethical diversity make it harder or even impossible for a theory's aims to obtain, thus making the theory 'unrealistic'. The connection with the challenge of consistency, then, becomes rather evident. Just recall our example of the conflict between religious freedom and security. That is perhaps the clearest way in which we can imagine how increased conditions of diversity could bring about an inconsistency within a theory. In that example indeed, the inconsistency affects two of the theory's explicit normative

criterion for the justification of normative political theories, regardless of any other consideration. Surely that does not shine as a very balanced position. 
commitments, i.e. two prescriptions contained in the theory or entailed by it. And that is also a typical example of a problem which would be captured by the labels of 'stability' or 'realism', as I have just characterized them.

Thinking about the problems of stability or realism in terms of clashes between explicit commitments of a normative political theory makes the connection between these problems and the challenge of consistency particularly evident. However, we should also consider the possibility of clashes between implicit commitments, or between implicit and explicit ones. Indeed, considering this sort of inconsistency seems especially useful in order to think about problems of 'realism'. The idea here is that the lack of 'realism' could be conceptualized as an inconsistency between one of the theory's explicit commitments or aims (avoiding violence between the citizens, say), and an implicit commitment that we can take any theory to have, namely that of being actually applicable. The intuitive point, then, is that there can be states of the context where the theory is meant to be applied which make it impossible for (some of) the theory's aims to obtain. For example, if-as I have just suggested-we consider a hypothetical theory which has as one of its primary and essential aims that of avoiding conflict and strife among the citizens it is meant to govern, we can easily imagine how conditions of radical ethical diversity could jeopardize such a goal. Hence the 'realism' parlance: if only the reality of the context of application of the theory were different, the theory would work (i.e. be applicable; or, rather, consistent, to use the terminology of the conceptual framework outlined here).

Having presented the basic model of the problems, let us now briefly consider how they play out in the debates on the foundations of liberal democracy, paying particular attention to the debate on citizenship and participation. A first, quite intuitive, example of the challenge of consistency at work is offered by arguments of a somewhat historical or sociological bend, such as those which criticize liberal democracy (or a particular form of liberal democracy) as 'outdated', 'unfit for modern societies', or even 'utopian'. The basic idea, usually supported by some empirical claims, is that liberalism was devised in rather homogeneous societies (seventeenth-century England, post-Westphalia Europe, and the like), and that its normative commitments were made to measure for those societies, as it were; however, the much higher level of diversity present in contemporary societies makes it impossible for a liberal political order to honour its commitments (Gray 2000, Parekh 1998). These sorts of arguments are often supported by considerations on the notion of citizenship: if there are no shared normative commitments, citizens will be unable or unwilling to engage in participatory deliberation with the requisite commitment to treat fellow citizens as free and equal partners. Thus, the arguments usually proceed, liberal societies are bound to become 'unstable', or to fade away, or need radical reform, and so on. It is easy to see the conceptual pattern of the challenge of consistency here: again, this is precisely the structure of the example of the clash between religious freedom and security. The other example I just presented, that of the difficulty of realistically containing conflict within a society characterized by radical ethical diversity, could also be a typical instance of the sort of arguments I have in mind here.

Those are all abstract, crudely simplified examples-perhaps it would be useful to also consider an example from the literature. Rawls' Political Liberalism could be a good candidate, for it seems to me that it can be understood precisely as addressing the challenge of consistency. Moreover, Rawls' characterization of the issues he takes himself to be addressing in the book seems to point towards an assimilation of matters of 'realism' and 'consistency', in a way which is nicely congruent with the conceptual framework outlined 
here. ${ }^{12}$ The main problem addressed by Rawls in Political Liberalism is usually presented as having to do with whether the prospect of a legitimate liberal democratic state in a society characterized by (a certain level of) ethical diversity is a realistic one: the book spells out a new conception of the legitimacy (i.e. of the criteria for public justification) of a liberal regime, in order to show how it is not unrealistic to aim to reconcile the goals of a wellordered liberal political regime with the fact of ethical diversity. Now, it may be interesting to note how Rawls, in a text such as Political Liberalism, which aims to point out and correct a major problem in his earlier work (Rawls 1971), and in which he reformulates his entire view on the justification and legitimacy of liberal theory, uses the terms 'inconsistent' and 'unrealistic' almost interchangeably (Rawls 1993, xviii-xix). More precisely, he says that an inconsistency in the theory of justice as fairness causes it to be unrealistic in a given context; thus he refers to the problem in the theory, which he terms 'the question of stability', both as one of 'consistency' and as one of 'realism'. In a nutshell, Rawls' point is that, given that a consensus on the part of the governed is a necessary condition for the legitimacy of a liberal polity (otherwise it would not be 'stable' - in a pragmatic and, most importantly, in the moral sense of 'stability for the right reasons), and that it is not realistic to expect citizens of an ethically diverse society to converge on a comprehensive doctrine (i.e. a doctrine covering nearly all aspects of what is valuable in human lives) as the justificatory basis for the fundamental principles regulating political life, it becomes necessary to (re)define liberalism as a non-comprehensive doctrine, unless we want to incur an inconsistency between the aim of securing a consensus and that of offering a comprehensive moral doctrine (as, in Rawls' view, is the case in A Theory of Justice). Also notice how, in line with what we observed above, this way of putting the problem is particularly relevant for the debate on citizenship, for Rawls outlines his solution to the problem, i.e. his theory of legitimacy through public justification, as a set of prescriptions he subsumes under the requirements 'the duty of civility' (1993, 271f.).

Thus it should be clear by now how the problem Rawls detected in the structure of $A$ Theory of Justice can be understood to stem from a failure to cope with what I have called the challenge of consistency: it is the fact of diversity that makes it impossible to reconcile in a coherent whole the aim of legitimacy through consent of the governed and that of providing a comprehensive moral doctrine. And, as suggested above, Rawls' own way of characterizing the problem he found in Theory supports my analysis of the problems of stability or realism in terms of consistency.

That is a very sketchy presentation of what some of the issues generated by the challenge of consistency in the debates on the justification of liberalism are; by no means should it be taken as an exhaustive list. It is rather a sort of conceptual compass, which should help us make sense of a rather vast and diverse body of literature. Our next step shall be to try to outline a strategy for assessing the importance of such issues, and, more importantly, for determining how best to engage with them. I will do that in the concluding section. Before that, however, let us return to the other focal point of our conceptual mapping of the problems connected to the fact of ethical diversity, namely what I have termed the challenge of adequacy.

\footnotetext{
${ }^{12}$ Rawls also talks about a problem of 'stability' with regard to those matters. However his sense of 'stability' is different from the one I employed here. Rawls' notion of the term expresses a combination of pragmatic and moral concerns. My usage of 'stability', as I hope to have made clear, is roughly that of common sense; hence it is more weighted on the pragmatic side.
} 


\section{Adequacy and Pluralism}

The challenge of adequacy is connected to a vast array of issues in the debates on the justification of liberalism; however, for our present purposes, it is neither necessary nor possible to explore them all. In fact, providing an account of all the issues that can be discussed in the terms of this challenge would go far beyond our aims here: as stressed above, I just intend to sketch a framework to think about some debates, and I do not aspire to illustrate exactly how to read every one of them. Rather, I shall make a few general points about the sort of arguments that are often developed in response to the challenge of adequacy, and then, as an illustration, briefly discuss how these sorts of arguments affect a recently much debated issue in the debates on the justificatory status of liberalism.

The basic lesson we have learned from our account of the challenge of adequacy is this. Ceteris paribus, theories which prescribe the inclusion of a large plurality of values and conceptions of the good tend to have a justificatory advantage over less inclusive ones. More precisely, it is not the case that the more inclusive a theory is, the better it is. Rather, it should aim to achieve a certain level of symmetry between what we have called the phenomenal or prima facie structure of value, and the values promoted, included or even just tolerated by the theory. In doing this, of course, a theory should maintain a justificatory balance, as it were, with its normative commitments (but, as we shall see shortly, the challenge can also generate a temptation to overlook this balance in favour of the pursuit of symmetry between prima facie and 'real' value). So for example, on this model a strongly perfectionist version of liberalism, which attaches high value to (say) civic virtues and rational autonomy, and thus actively promotes those values at the expense of others that are however commonly perceived as equally important (e.g. religious commitment), would be at a justificatory disadvantage against a neutralistic version of liberalism, which would grant equal treatment to all those values. ${ }^{13}$ Very roughly, the idea here seems to be that, the higher the symmetry, the less demanding our standards for accepting the arguments in support of the theory will become.

This last point could help explain a recent trend in the debates on the justification of liberalism, namely that of discussing the 'implications of value pluralism'-hopefully that will be a good illustration of how the challenge of adequacy can affect those debates. Indeed, the issue of the relation between the justificatory status of liberalism and a theory of value labelled 'value pluralism' has been rather fashionable in recent political philosophy (Crowder 2002, chaps 4-5, Dzur 1998, Newey 1998). Some theorists have indeed presented value pluralism as the key to breaking the deadlock of the dispute between deontological and teleological justifications of liberalism, thus injecting new lifeblood into a now somewhat anemic debate (Berlin and Williams 1994, Crowder 2002, Galston 2002, Lukes 1991). Others have argued that value pluralism seriously undermines the project of justifying liberalism altogether (Crowder 1994, Kekes 1992, Newey 1998). Intermediate positions, of course, have been put forward too ( $\operatorname{Raz} 1986$, Gray 2000). What is more, there is little if any sign of a convergence towards a mainstream view about this issue. That is somewhat puzzling,

\footnotetext{
${ }^{13}$ The point about justificatory balance, of course, leaves all the room necessary for perfectionist liberalism to compensate this weakness with other strengths-for example it could be supported by arguments showing how its substantial values have a better impact on well-being than the impartial ones embodied by the neutralistic version of liberalism. As I pointed out, the issues raised by the challenge of adequacy should not be taken as the ultimate tribunal for matters of justification of a normative political theory.
} 
when one considers that the participants in the debate usually present their arguments as mainly consisting of an analysis of the implications of value pluralism for liberalism: it seems unlikely that so much disagreement is possible in spelling out the implications of a clearly individuated theory of value. Perhaps, then, there is something misleading about the way the debate has been conducted so far. Barring the unlikely scenario that the disagreement is due to mistakes (which would have to be rather gross) leading to conclusions which do not follow from the value-pluralistic premises, and assuming that there is sufficient agreement about what liberalism is, a suspicion arises that the participants in the debate may be talking past each other. ${ }^{14}$ Now, in the light of the remarks on the challenge of adequacy above, it does not seem too bold to advance the conjecture that perhaps the enthusiasm induced by the challenge of adequacy for theories recognizing a high level of symmetry between prima facie and real value could explain why the participants in the debates have been so quick, perhaps too quick, to embrace a not very carefully characterized theory of value (the point being, of course, that this 'carelessness' could be one of the main reasons for the apparent equivocation). In other words, pluralist supporters and critics of liberalism could have been lured by the challenge of adequacy to lower their standards for the endorsement of a theory of value, in the hope of tipping the ultimate justificatory balance on their side thanks to the high level of symmetry between prima facie value and the 'real' structure of value as it is usually presented in the various versions of 'value pluralism'.

So, for the purposes of using our characterization of the challenge of adequacy as a conceptual compass, the more general point which emerges from this conjecture is that the challenge of adequacy tends to invite attention to the final effect of a theory in terms of inclusiveness towards ethical diversity, while deflecting it from the arguments and considerations which are needed to support such an effect. To put it more crudely, whether a theory is inclusive risks becoming more important than whether such inclusion is well argued for. That need not be taken as a conceptual point on the effect of the challenge, though; it is rather a modest conjecture deriving from the observation of some recent trends in the literature, and it should be taken with the proverbial grain of salt. However, discussing these general matters is perhaps more suited to the concluding section, to which we can now turn.

\footnotetext{
${ }^{14}$ Investigating how exactly this could be the case would lead us very far away from our current focus. For the moment, all I can offer is a couple of conjectures, as to how the participants in the liberalismvalue pluralism debate may be talking past each other. On the one hand, they may be referring to different conceptions of value pluralism, and thus be talking past each other in a rather trivial sense. This possibility does not seem at all remote, if one considers how little interaction there has been between the value pluralism-debate in political philosophy and the rich literature on value pluralism and its implications that has grown in moral philosophy over the past three decades or so. On the other hand, the participants in the debate may be talking past each other in a less trivial sense, namely because value pluralism per se is not relevant for the justification of liberalism, but a discussion of its nature and implications is connected to, highlights or perhaps even generates other issues that are relevant. If this is the case, the debate rests largely on an equivocation, and the real disagreement is about some other issue (one may say, slightly paradoxically, that in this way they are talking past each other for good reasons): what is actually being discussed in the debate on 'the implications of value pluralism' could then be one (or more) of the traditional controversies on the foundations of liberalism, or perhaps a genuinely new issue (which of course is not best characterized as 'value pluralism'), or a combination of the former and the latter. If this second hypothesis is correct, our first task should of course be to try to provide an account of what in fact is at stake in the debate.
} 


\section{Concluding Remarks}

So far we have seen that the arguments for and against liberal democracy which proceed from the fact of ethical diversity can be understood as stemming from one out of two potential sources of problems for the justificatory status of a normative political theory, which we have termed the challenge of consistency and the challenge of adequacy. The former arises because diversity often causes clashes between the prescriptions generated by normative political theories; the latter emerges as diversity generates a rift between our experience of what is considered valuable and what the theory treats as such. We have then seen how those challenges can be used to read many of the current debates on the foundations of liberalism, especially as regards problems to do with the role and regulation of participatory citizenship, and with the reconciliation of liberal political practice with controversial theories of value. Now, since it has not been my aim here to argue for any particular normative position, but rather to just clarify the senses in which we can say that normative political theories face a challenge when confronting the fact of pluralism, let me conclude by simply offering a few questions for further work on the issue of liberal democracy's troubled relationship with diversity, in the light of the analysis carried out in the previous sections.

Regarding the challenge of adequacy, from our brief discussion at least two interesting issues emerge, one general (i.e. related to most areas of the debate), one particular (i.e. connected to just one branch of the debates). The particular issue, of course, is that of the role of the challenge of adequacy in the liberalism-value pluralism debate. It may be worthwhile exploring the reasons why the debate has been so inconclusive; in doing this, the conjecture I outlined here might prove a useful starting point, even if it were to prove false as an explanatory hypothesis. Finally, the general issue is that of what I have called the 'justificatory balance' that theories should strive for when addressing the challenge of adequacy. It may prove interesting to analyse some controversies over the foundations of liberalism (for example that between neutralistic or deontological vs. teleological liberalism) in terms of an effort of balancing the intuitive appeal of inclusiveness against more theoretically-led arguments in favour of a particular position.

As for the challenge of consistency, we have seen how it picks out an important class of issues in the debates on the foundations of liberal democracy. It seems to me that the problems presented above should lead us to take historically-informed arguments for, and in particular against liberalism, more seriously than has often been the case in much recent literature. That should enable us to make sense of a rather large body of literature which perhaps has not received as much consideration as it deserves. To mention a more specific issue, it would presumably be illuminating to provide a full analysis of Rawls' Political Liberalism informed by our characterization of the challenge of consistency. That could indeed prove a good way of finding out whether Rawls has been successful in correcting the problems he detected in A Theory of Justice and, more generally, whether neutralistic liberalism (of which Political Liberalism is quite uncontroversially the flagship text), with its accompanying idea of public reason-bound participatory citizenship, can succeed in formulating criteria for the legitimacy of liberal democratic political practice that are suitable for the conditions of the persistent diversity of contemporary societies. 


\section{References}

Bardone, E., Rossi, E. (Eds.). Oltre le culture. Valori e contesti della comunicazione interculturale. Como and Pavia: Ibis, 2004.

Berlin, I., Williams, B. Pluralism and Liberalism: a Reply. Political Studies, XLI: 306-309, 1994.

Carter, I. "L'incommensurabilità dei valori e il diritto alla libertà". In E. Bardone, E. Rossi (Eds.). Oltre le culture. Valori e contesti della comunicazione interculturale. Como and Pavia: Ibis, 2004.

Crowder, G. Pluralism and Liberalism. Political Studies 42, 293-305, 1994.

Crowder, G. Liberalism and Value Pluralism. London and New York: Continuum, 2002.

D'Agostino, F. Pluralism and Liberalism. In G.F. Gaus, Chandran Kukathas (Eds.). Handbook of Political Theory. Ithaca: Sage, 2004.

Dzur, A.W. Value Pluralism vs. Political Liberalism? Social Theory and Practice 24, 375-392, 1998.

Galasso, G. Storia d'Europa. Roma-Bari: Laterza, 1996.

Galston, W.A. Liberal Pluralism: The Implications of Value Pluralism for Political Theory and Practice. Cambridge: Cambridge University Press, 2002.

Gray, J. Pluralism and Toleration in Contemporary Political Philosophy. Political Studies 48, 323-333, 2000.

Kekes, J. The Incompatibility of Liberalism and Pluralism. American Philosophical Quarterly 29, 141-51, 1992.

Larmore, C. Pluralism and Reasonable Disagreement. Social Philosophy and Policy 11, 61-79, 1994.

Lukes, S. Moral Conflict and Politics. Oxford: Clarendon Press, 1991.

McLennan, G. Pluralism. Buckingham: Open University Press, 1995.

Newey, G. Value Pluralism in Contemporary Liberalism. Dialogue 37, 493-522, 1998.

Parekh, B. Rethinking Multiculturalism: Cultural Diversity and Political Theory. London: Palgrave Macmillan, 2000.

Rawls, J. Political Liberalism. Second Edition. New York: Columbia University Press, 1993.

Raz, J. The Morality of Freedom. Oxford: Clarendon Press, 1986.

Shklar, J. The Liberalism of Fear. In Rosenblum, N. (Ed.). Liberalism and the Moral Life. Cambridge, MA: Harvard University Press, 1989.

Social Ethics Research Group

School of Health and Social Sciences

University of Wales, Newport

Caerleon Campus, Lodge Road

Caerleon, Newport

NP18 3NT

E-mail: enzo.rossi@newport.ac.uk 